\title{
A 24-year-old female with anti-N-methyl-D-aspartate receptor encephalitis: a case report
}

Antoine Steeman ( $\Delta$ antoine.steeman@gmail.com )

ULB: Universite Libre de Bruxelles https://orcid.org/0000-0002-5911-1421

\section{lonut-Adrian Andriescu}

CHA: Hopital de Libramont

\section{Guy Mazairac}

CHA: Hopital de Libramont

\section{Case report}

Keywords: Neurology, psychosis, autoimmune encephalitis, confusion

Posted Date: February 4th, 2021

DOl: https://doi.org/10.21203/rs.3.rs-105688/v2

License: (1) This work is licensed under a Creative Commons Attribution 4.0 International License. Read Full License 


\section{Abstract}

Background: Anti-N-methyl-D-aspartate (NMDA) receptor encephalitis is a form of autoimmune encephalitis with paraneoplastic and nonparaneoplastic origin. Anti-NMDA receptor encephalitis preferentially affects children and young adults with a male/female ratio of $1 / 4$. In case of clinical suspicion, electroencephalogram and brain magnetic resonance imaging (MRI) are useful. The diagnosis is confirmed by the detection of IgG antibodies directed against NMDA receptors. Treatment includes immunosuppression and tumour resection when indicated.

Case Report: We report the case of a 24-year-old female admitted to the emergency room following the onset of acute confusion. Due to the rapid deterioration of consciousness and swallowing disorders, the patient was transferred to the intensive care unit. On day 23 after presentation, MRI suggested autoimmune limbic encephalitis. Serologic and cerebrospinal fluid results were positive for anti-NMDA antibodies. After intravenous methylprednisolone therapy and plasmapheresis and a second line therapy with corticosteroid therapy and mycophenolic acid, the patient's clinical condition gradually improved.

Why should an emergency physician be aware of this? : This disease is still underdiagnosed. The possibility of Anti-NMDA encephalitis must be excluded especially for young female adults and children presenting to emergency department with acute confusion before concluding a psychiatric disease diagnosis. Neurological deterioration typically occurs 1 to 3 weeks after the onset of symptoms.

\section{Introduction}

Anti-N-methyl-D-aspartate (NMDA) receptor encephalitis is a rare autoimmune disease that is frequently underdiagnosed. The pathophysiology of this disease results from the binding of anti-NMDA antibodies to NMDA receptors, causing neuronal dysfunction and the disruption of fronto-striatal connections.

The clinical presentation of this disease is manifested by non-specific influenza syndrome. Subsequently, acute psychiatric symptoms appear, such as agitation, visual and auditory hallucinations, anxiety, emotional lability, and disorganized thoughts. Neurological deterioration typically occurs 1 to 3 weeks after the onset of symptoms, including abnormal movements, seizures and autonomic nervous system disorders. This clinical picture is often complicated by altered consciousness, swallowing disorders and respiratory distress, which requires intensive care.

\section{Clinical Case}

We report the case of a 24-year-old female Belgian patient with no significant history who was admitted to the emergency department (ED) following the onset of acute confusion and fear of imminent death.

Few days before her admission, she had rhinitis with sore throat. In the emergency department, she presented agitation, hallucinations, echolalia with ideas of death and aggression. Laboratory testing demonstrated no abnormalities, with a normal white blood cell count and normal C-reactive protein. 
Toxicology screening, electroencephalogram (EEG) and brain scan were also normal. The patient was hospitalized for an additional assessment.

At first, there was a spontaneous resolution of her psychiatric symptoms. Two days later, the reappearance of agitation, impulsive aggression, and visual hallucinations led to psychiatric hospitalization. After four days, her clinical condition worsened, including impaired consciousness, pyrexia, tachycardia, swallowing disorders and food refusal.

The patient was transferred from the psychiatric department to the ED for suspected neuroleptic malignant syndrome. In the ED, she presented a state of mutism and stupor with fever, tachycardia, tachypnea, muscle rigidity and swallowing disorders.

Laboratory testing revealed inflammatory syndrome (C-reactive protein: $44 \mathrm{mg} / \mathrm{l}$ ) but infectious serology (borrelia, cytomegalovirus, Epstein-Barr virus) and serologic screening for autoimmune diseases (antineutrophil cytoplasmic antibodies, anti-nuclear antibodies) were normal. Toxicologic screening, EEG and brain magnetic resonance imaging (MRI) findings were also normal. Lumbar puncture revealed transparent cerebrospinal fluid (CSF) and polymerase chain reactions for herpes zoster, enterovirus and herpes simplex on CSF were normal. Blood and CSF cultures were negative. Futher immunologic blood tests and CSF were sent to a university laboratory.

Due to the deterioration of consciousness, swallowing disorders, respiratory distress syndrome and severe bradycardia, the patient was intubated and transferred to the intensive care unit (ICU).

On day 23, a new Brain MRI fluid-attenuated inversion recovery (FLAIR) was performed and showed the presence of a hyperintense signal on involving temporal and limbic lobes (see figure 1), suggesting autoimmune limbic encephalitis. Pulsed therapy with $1 \mathrm{~g} / \mathrm{d}$ methylprednisolone was initiated, and neuroleptics were stopped.

The patient continued to develop dysautonomia disorders (low blood pressure, tachycardia, apnoea and Cheyne-Stokes respiration) as well as episodes of acute agitation.

A serologic test and CSF results showed the presence of specific IgG oligoclonal bands and were positive for anti-NMDA antibodies. The 48-hour EEG did not demonstrate any epileptogenic activity. The PET scanner for oncology check-up was negative.

Finally, the patient benefited from intravenous methylprednisolone therapy as well as 10 plasmapheresis sessions, followed by oral corticosteroid therapy. The patient's clinical condition gradually improved, and she was transferred to the neurology department.

A neuropsychological and neurological assessment showed a pyramidal syndrome with proximal predominant left hemiparesis, a deficit in verbal fluency and pathological denomination. 
Clinical progress was slow but favourable with corticosteroid therapy and mycophenolic acid treatment. The patient returned home after 56 days of hospitalization. At an 18-month follow-up, there was no recurrence, and the PET scanner remained negative.

\section{Discussion}

Anti-NMDA receptor encephalitis preferentially affects children (from 8 months old) [1] and young adults (less than $5 \%$ of patients are over 45 years old [2]) with a male/female ratio of $1 / 4$ [3].

The origin of this disease is often paraneoplastic. Approximately $50 \%$ of women over 18 years old and only $9 \%$ of girls under 14 years old have an ovarian teratoma [4]. In men, the presence of tumours is rare [5].

The diagnosis of anti-NMDA receptor encephalitis should be discussed in the presence of a suggestive clinical picture and signs, such as lymphocytic pleocytosis and IgG oligoclonal bands in the CSF; abnormal EEG results in the majority of cases but nonspecific with a slow and disorganized epileptic activity [6]. Brain MRI is often normal. In the study of Dalmau et al. [6] only $55 \%$ of patients had increased FLAIR or T2 signal in the cortical or subcortical areas (hippocampus, basal ganglia, white matter). The diagnosis is confirmed by the detection of IgG antibodies directed against the GluN1 subunits of the NMDA receptors in serum and CSF [7].

The differential diagnosis includes acute primary psychiatric disorder, neuroleptic malignant syndrome, malignant catatonia [8], viral encephalitis [9], and lethargic encephalitis [10].

However, the diagnosis of anti-NMDA receptor encephalitis remains difficult due to the vagueness of the primary clinical picture. In a study [10] anti-NMDA antibodies are found in $50 \%$ of patients diagnosed with lethargic dyskinetic encephalitis. Additionally, $20-30 \%$ of patients with herpes simplex virus (HSV) infection show positive seroconversion with anti-NMDA antibodies as part of a relapse not attributable to HSV relapse [11].

In the absence of reliable statistical data, there is no standard treatment; instead, treatment should be individualized according to age, the severity of symptoms, and the presence or absence of a tumour. Treatment can include immunosuppression and tumour resection when indicated [4].

Some therapeutic variants for the initial immunosuppressive treatment are recommended, including either an intravenous infusion of methylprednisolone ( $1 \mathrm{~g} /$ day for 5 days) or intravenous treatment with immunoglobulin $\mathrm{G}$ (400 mg/kg/day for 5 days) or plasmapheresis [12].

In the absence of clinical improvement, second-line treatment with rituximab $\left(375 \mathrm{mg} / \mathrm{m}^{2} /\right.$ week for 4 weeks) or cyclophosphamide (750 mg/m²/month for 4 to 6 months) or a combination of both molecules can be proposed [12]. Mycophenolate mofetil can also be used as second line therapy. This drug has a 
selective antiproliferative activity on lymphocytes and has shown better efficacy in inducing remission. Furthermore, it has less side effect profile than cyclophosphamide in other autoimmune disorders [13].

Finally, for patients with severe and treatment-refractory disease, bortezomib [14] or tocilizumab [15] can be used as third-line therapy.

In addition, patients may require long-term care in intensive care from several weeks to several months as well as multidisciplinary rehabilitation.

NMDA anti-receptor IgG crosses the placental barrier, and its effects on the foetus can be variable; case of early neonatal death has been described previously [16].

\section{Why should an emergency physician be aware of this?}

Our case highlights the fact that for every young person presenting to emergency department with a clinical manifestation of acute confusion without any medical history of psychiatric disorder, an organic neurological or toxic origin must be excluded.

Anti-NMDA receptor encephalitis typically occurs in young patients with no history of acute psychiatric symptoms. This disease is still underdiagnosed due to the variability of the initial symptoms. Anti-NMDA encephalitis presents with a prodrome of viral-like symptoms. Neurological deterioration typically occurs 1 to 3 weeks after the onset of symptoms, including abnormal movements, seizures and autonomic nervous system disorders. The origin is often paraneoplastic. In case of clinical suspicion, EEG and brain MRI are useful, but lumbar puncture for CSF analysis is used to confirm the diagnosis. Treatment includes immunosuppression and tumour resection when indicated.

The possibility of Anti-NMDA encephalitis must be excluded especially for young female adults and children presenting to ED with acute confusion before concluding with a psychiatric disease diagnosis.

\section{Conclusion}

Anti-NMDA receptor encephalitis typically occurs in young patients with no history of acute psychiatric symptoms. This disease is not well known and underdiagnosed due to the variability of the initial symptoms. Neurological deterioration typically occurs 1 to 3 weeks after the onset of symptoms, including abnormal movements, seizures and autonomic nervous system disorders. The origin is often paraneoplastic. In case of clinical suspicion, EEG and brain MRI are useful, but lumbar puncture for CSF analysis is used to confirm the diagnosis. Treatment includes immunosuppression and tumour resection when indicated. The possibility of this pathology should be taken into account before diagnosing a patient with a psychiatric illness.

\section{List Of Abbreviations}

NMDA 
Anti-N-methyl-D-aspartate; EEG:electroencephalogram; CSF:cerebrospinal fluid; ICU:intensive care unit; FLAIR:fluid-attenuated inversion recovery; HSV:herpes simplex virus.

\section{Declarations}

- Ethics approval and consent to participate

Not applicable

- Consent for publication

The patient give his content for all part of the material referenced here.

- Availability of data and materials

Please contact author for data requests.

- Competing interests

Not applicable

- Funding

The authors declare that they received no funding

- Authors' contributions

All authors were major contributors in writing the manuscript. The authors read and approved the final manuscript.

- Acknowledgements

Not applicable

\section{Bibliography}

1. Armangue T, Titulaer MJ, Málaga I, Bataller L, Gabilondo I, Graus F, et al. Spanish Anti-N-methyl-DAspartate Receptor (NMDAR) Encephalitis Work Group. Pediatric anti-N-methyl-D-aspartate receptor encephalitis-clinical analysis and novel findings in a series of 20 patients. J Pediatr. 2013 Apr;162(4):850-856.e2. DOI: 10.1016/j.jpeds.2012.10.011.

2. Titulaer MJ, McCracken L, Gabilondo I, lizuka T, Kawachi I, Bataller L, et al. Anti-NMDA receptor encephalitis. Neurology. 2013 Sep 17;81(12):1058-63. doi: 10.1212/WNL.0b013e3182a4a49c.

3. Mann AP, Grebenciucova E, Lukas RV. Anti-N-methyl-D-aspartate-receptor encephalitis: diagnosis, optimal management, and challenges. Ther Clin Risk Manag. 2014 Jul 1;10:517-25. doi: 
10.2147/TCRM.S61967.

4. Titulaer MJ, McCracken L, Gabilondo I, et al. Treatment and prognostic factors for long-term outcome in patients with anti-NMDA receptor encephalitis: an observational cohort study. Lancet Neurol. 2013;12(2):157-165. doi: 10.1016/S1474-4422(12)70310-1.

5. Lancaster E, Martinez-Hernandez E, Dalmau J. Encephalitis and antibodies to synaptic and neuronal cell surface proteins. Neurology. 2011 Jul 12;77(2):179-89. doi: 10.1212/WNL.0b013e318224afde.

6. Dalmau J, Gleichman AJ, Hughes EG, et al. Anti-NMDA-receptor encephalitis: case series and analysis of the effects of antibodies. Lancet Neurol. 2008;7(12):1091-1098. doi: 10.1016/S14744422(08)70224-2.

7. Prüss H, Dalmau J, Harms L, Höltje M, Ahnert-Hilger G, Borowski K, et al. Retrospective analysis of NMDA receptor antibodies in encephalitis of unknown origin. Neurology. 2010 Nov 9;75(19):1735-9. doi: 10.1212/WNL.0b013e3181fc2a06.

8. Sansing LH, Tüzün E, Ko MW, Baccon J, Lynch DR, Dalmau J. A patient with encephalitis associated with NMDA receptor antibodies. Nat Clin Pract Neurol. 2007;3(5):291-296. doi:10.1038/ncpneuro0493.

9. Gable MS, Gavali S, Radner A, Tilley DH, Lee B, Dyner L, et al. Anti-NMDA receptor encephalitis: report of ten cases and comparison with viral encephalitis. Eur J Clin Microbiol Infect Dis. 2009 Dec;28(12):1421-9. doi: 10.1007/s10096-009-0799-0.

10. Dale RC, Irani SR, Brilot F, Pillai S, Webster R, Gill D, et al. N-methyl-D-aspartate receptor antibodies in pediatric dyskinetic encephalitis lethargica. Ann Neurol. 2009 Nov;66(5):704-9. doi:

10.1002/ana.21807.

11. Armangue T, Spatola M, Vlagea A, Mattozzi S, Cárceles-Cordon M, Martinez-Heras E, et al.; Spanish Herpes Simplex Encephalitis Study Group. Frequency, symptoms, risk factors, and outcomes of autoimmune encephalitis after herpes simplex encephalitis: a prospective observational study and retrospective analysis. Lancet Neurol. 2018 Sep;17(9):760-772. doi: 10.1016/S1474-4422(18)302448.

12. Shin YW, Lee ST, Park Kl, et al. Treatment strategies for autoimmune encephalitis. Ther Adv Neurol Disord. 2017;11:1756285617722347. Published 2017 Aug 16. doi:10.1177/1756285617722347.

13. Ginzler EM, Aranow C. Mycophenolate mofetil in lupus nephritis. Lupus. 2005;14(1):59-64. doi: 10.1191/0961203305lu2061oa.

14. Shin YW, Lee ST, Kim TJ, Jun JS, Chu K. Bortezomib treatment for severe refractory anti-NMDA receptor encephalitis. Ann Clin Transl Neurol. 2018;5(5):598-605. Published 2018 Mar 23. doi: 10.1002/acn3.557.

15. Lee WJ, Lee ST, Moon J, et al. Tocilizumab in Autoimmune Encephalitis Refractory to Rituximab: An Institutional Cohort Study. Neurotherapeutics. 2016;13(4):824-832. doi: 10.1007/s13311-016-0442-6.

16. Chourasia N, Watkins MW, Lankford JE, Kass JS, Kamdar A. An Infant Born to a Mother With Anti-NMethyl-d-Aspartate Receptor Encephalitis. Pediatr Neurol. 2018 Feb;79:65-68. https://doi.org/10.1212/NXI.0000000000000668. 
Figures

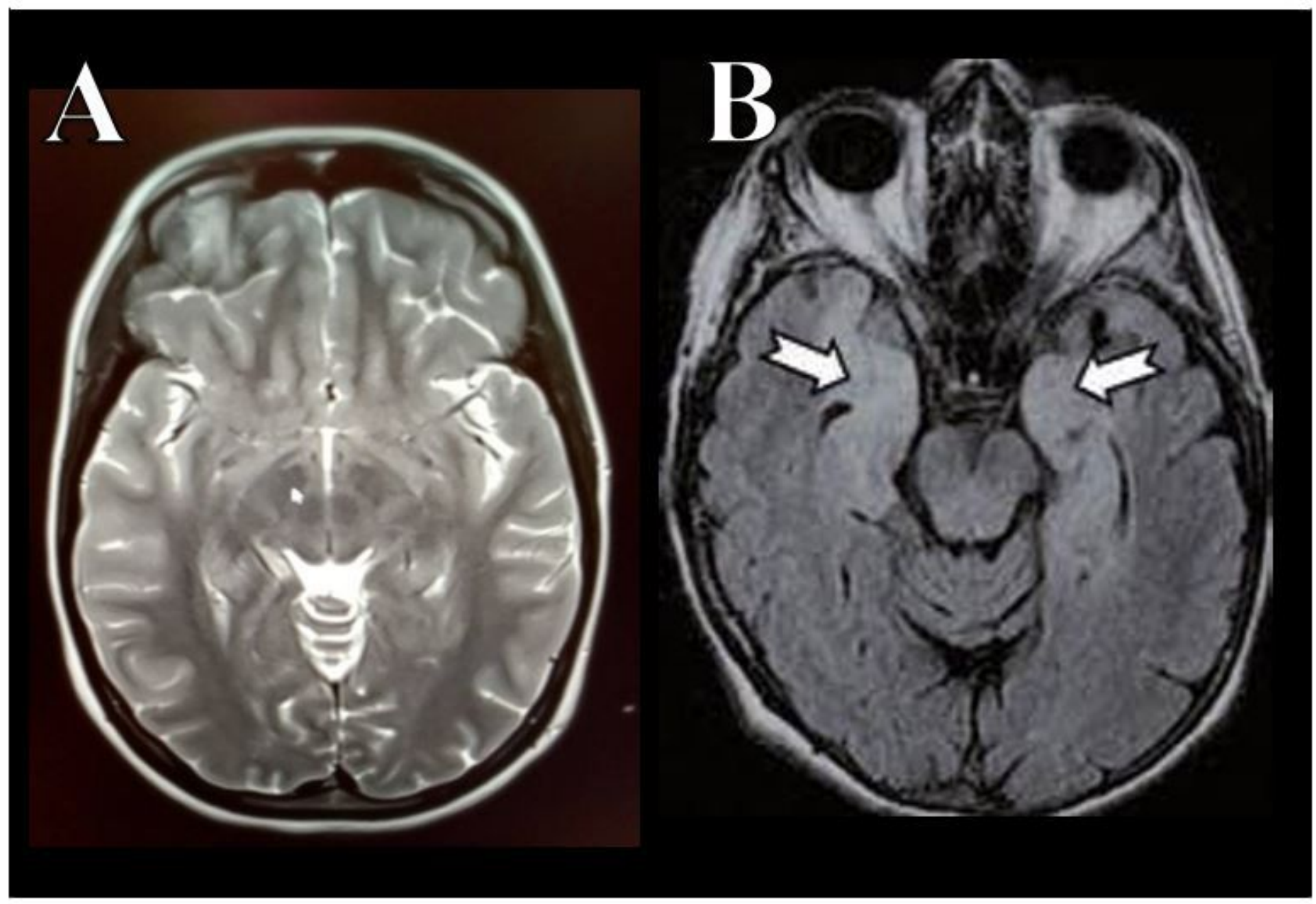

Figure 1

23 days after symptom onset, brain MRI fluid-attenuated inversion recovery $(A)$ revealed limbic encephalopathy with hyperintense signal involving temporal and hippocampus (arrows) (B). 